\title{
Erosion Corrosion Behavior of Nanostructure Commercial Pure Titanium in Simulated Body Fluid
}

\author{
F. Djavanroodi ${ }^{1,2 a}$, Osama M. Irfan ${ }^{3}$, and Fahad A. Al-Mufadi ${ }^{3}$ \\ 1Mechanical Engineering Department, Prince Mohamed Bin Fahad University, KSA \\ 2Mechanical Engineering Department, Imperial College, London, UK \\ 3Mechanical Engineering Department, Engineering College, Qassim University, KSA
}

\begin{abstract}
To date, ECAP technique have been successfully employed to produce Ultra-fine/Nanostructure grain materials, but some materials such as hexagonal closed-packed (HCP) alloys are difficult to process by ECAP at room temperature. In this work, Transmission Electron Microscopy (TEM), Vickers hardness test and Torsion test were employed to confirm the attainment of ultrafine/nanostructured grain (UFG/NSG) commercial pure titanium (CP-Ti) Titanium fabricated by ECAP as a sever plastic deformation process. The samples were pressed by ECAP (route BC) up to four passes at elevated temperature $\left(400^{\circ} \mathrm{C}\right)$. Finally, the Erosion-Corrosion (E-C) behavior of ultrafine/nanostructured grain (UFG/NSG) Titanium in a simulated body fluid were investigated through weight loss measurement.
\end{abstract}

\section{INTRODUCTION}

During the last two decades of the twentieth century, titanium and titanium alloys gained much attractiveness and acceptance in engineering and medical applications due to exceptional strength, lower elastic modulus, and greater compatibility with human tissues. Moreover, titanium is no longer viewed as an exotic material for the aerospace industry and it has been used in many non-aerospace application such as turbines blade, compressors blades, marine structure, hydraulic systems, golf club and implants. [1-2]. Tailoring grain size to enhance physical and mechanical properties of material to specific application requirements is one of the major challenges in materials engineering. One of ways to grain refinement of bulk metals is the use of severe plastic deformation (SPD) methods. Equal channel angular pressing (ECAP) is most widely used technique for fabricating (UFG/NSG) metals and alloys such as titanium, aluminum, steel, and Mg alloys [3-8].

Erosion-Corrosion (E-C) is a form of tribo-corrosion, which can cause considerable material loss due to number of factors namely, impacting particle, the target and the aqueous medium. E-C is attributed to a combination of chemical and mechanical effects that may cause a surface destruction [1]. Two mechanisms have been suggested to elucidate the erosion corrosion behavior [9 and 10]. The first is the degradation of the strength or surface hardness due to erosion - corrosion. The other mechanism is removal of passive protective thin layer on the surface by the erosion. There are two classification for erosion-corrosion: erosion-enhanced corrosion (EEC) in which the surface damage is limited to the passive protective thin layer, and corrosion-affected erosion (CAE), in which the surface damage includes both the oxide and the metal [11]. Many industrial equipment's are exposed to the E-C problem (turbine blades, compressors blades, hydraulic systems, valves, pipelines, heat exchangers and pressure vessels). Nevile and McDougal [1] used impinging jet apparatus to study the erosion-corrosion of grade 2 titanium at 18 and $50^{\circ} \mathrm{C}$. They have shown that under erosion-corrosion conditions the material exhibit active corrosion behavior, in contrast to passive behavior under corrosion. The synergistic effect between erosion and corrosion is significant. Berm'udez et. al. studied Erosion-corrosion of stainless steels, titanium, tantalum and zirconium under an aqueous solution containing $\mathrm{Al} 2 \mathrm{O} 3$ particle and $10 \mathrm{wt} \% \mathrm{HCl}$. For Ti it was shown that, eroded protected surface shown no sign of corrosion due to passive oxide layer. On the other hand, the erosion-corrosion exposed region showed rough surface with cracks, only on the oxide scale. They concluded that the main mechanism is the erosionenhanced corrosion, in which the damage is confined within a thick scale while the base metal remains unaffected [11]. Titanium in the absence of erosion, the material surface is usually protected from the corrosive environment by formation of passive film which separates the surface from the corrosive environment. However, under E - C conditions, the surface passive film might be damaged or even removed by which it may lead in an increased corrosion rate [1].

There are limited studies on the E-C behavior of UFG/NSG materials $[12,13]$. Therefore, the current work addresses this issue, and compares the E-C resistance of commercial pure titanium CP-Ti with ultrafine/nanostructured grain (UFG/NSG) Titanium fabricated by ECAP as sever plastic deformation process in a simulated body fluid. 


\section{MATERIALS AND EXPERIMENTAL WORK}

In the current work a bar stock of CP-Ti (99.2\% purity) (ASTM Grade 2; UNS R50400) in the form of extruded rod of 20 $\mathrm{mm}$ diameter was used. The test bars were prepared from both coarse and ultra-fine grain (UFG/NSG) titanium. The UFG/NSG was achieved after four passes of ECAP process (route BC). The ECAP process were carried out at $400^{\circ} \mathrm{C} \pm 20$ with a ram speed of $3 \mathrm{~mm} / \mathrm{s}$. Molybdenum disulfide-based solid (MoS2) lubricant were used to reduce the friction. A 160 tons capacity hydraulic press with a ram speed of $3 \mathrm{~mm} / \mathrm{s}$ was used to conduct the ECAP. The details of the die and material flow direction and ECAP sample are shown in Figs. $1 \& 2$. Prior to ECAP process Ti rods were annealed at $710^{\circ} \mathrm{C}$ for 2 hours and then furnace cooled.

Zwick/Roell machine (Model ZHU250) was employed to measure Vickers hardness (HV) according to ASTM E92-04 standard. The HV values were recorded with respect to the number of ECAP passes. The torsion tests according to ASTM A938 standard were conducted on annealed and UFG-Ti samples. A torsion machine model ND-W500 was used for that purpose. The specimens before and after the torsion test are shown in Fig.3.

A slurry pot test rig was used for the E-C experiments. The setup of the slurry pot tester consisted of a cylindrical container in which the $\mathrm{E}-\mathrm{C}$ medium was placed. A rigid disc made of Teflon- $200 \mathrm{~mm}$ in diameter and $25 \mathrm{~mm}$ in thickness was attached to a stainless steel shaft. Both the disc and the shaft were coupled to the mandrel of a drilling machine. The drilling machine was equipped with a gearbox to provide various rotation speeds. The specimens were mounted to the disc at different radial positions to get various linear velocities. The setup of the slurry pot and specimen holder are shown in Figs 4. The E-C experiments were carried out according to ASTM G119 standard. Simulated body fluid was used as the test medium. Wire Electrical Discharge Machining (WEDM) was employed to cut the E-C samples (20 mm diameter and $6 \mathrm{~mm}$ thickness) from different ECAP passes. A high precision balance ( $0.1 \mathrm{mg}$ resolution) was used to weight the samples before and after the E-C tests. The average weight loss per unit area of three repeated tests was calculated. The experimental work are listed in Table 1.

Table 1. Erosion-Corrosion Experiments at constant velocity $\left(5.4 \mathrm{~m} / \mathrm{s}\right.$ and Impact angle $45^{\circ}$

\begin{tabular}{|l|l|l|l|l|}
\hline Experimental Time (hr) & 300 & 500 & 750 & 1000 \\
\hline
\end{tabular}

\section{RESULTS and DISCUSSION}

It has been demonstrated that the grain refinement during ECAP in route $\mathrm{BC}$, starts with grain elongation occurring in the initial passes, followed by gradual grain fragmentation. This results in the formation of an equi-axed grain structure after the four pass [3]. Fig. 5 shows the changes of microstructure due to the ECAP passes of CP-Ti at $400^{\circ} \mathrm{C}$. Fig. 1-(a) shows the optical microscopy of the as received annealed CP-Ti microstructure with an average grain size of about $30 \mu \mathrm{m}$. After four ECAP passes, the grain size decrease to almost $300 \mathrm{~nm}$ as shown in Fig. 1-(b).

The results of torsion test (Fig. 6) shows the effect of ECAP passes on both the yield and ultimate strengths of CP-Ti. In addition, the reduction percentage of ductility is shown. It is noticed an increase in the strength of CP-Ti after the ECAP. The yield and ultimate shear stresses increased by $65 \%, 16 \%$ and the ductility of the material decreased by $29 \%$ after four passes of ECAP, respectively.

Prior to any HV measurement, the oxide layer were removed from the surface. The variation of HV numbers with respect to ECAP passes are shown in Fig. 7. The graph shows a significant increase of hardness after the first pass. For further ECAP passes, the increasing rate of hardness is relatively lower. Furthermore, the increasing rate of hardness is almost gradually and uniform. The HV value after four ECAP passes was $248 \mathrm{HV}$. This is equivalent to about $50 \%$ enhancement of hardness as compared to the annealed conditions (166 HV). The rapid increase of hardness after the first pass can be attributed to the high magnitude of shear strain is imposed to the specimen causing the increment of dislocations density, formation of low angle grain boundaries, transformation of low to high angle grain boundaries, and generation of ultrafine grain (UFG) materials [14].

As it is evident in Fig. 7 with increasing the experimental time the rate of E-C increases for UFG/NSG and annealed CP-Ti samples. The rate of E-C decreases with increasing the ECAP passes and the least value is observed at four pass ECAP. One possible reason for the improvement can be interpreted as follows: The hardness of the annealed CP-Ti specimens was 
lower than the hardness of ECAPed specimens and as the hardness increased with increasing number of ECAP passes the weight loss due to E-C decreased. The decrease in E-C rate can be due to the increased interstitial content and resultant increased flow stress caused by strain hardening and strain rate hardening during SPD process [15]. However our results show this is not fully the case, the highest improvement achieved with the high hardness and good material homogeneity. This result also demonstrates that the inhomogeneous strain distribution produced by ECAP at the smallest number significantly influences the erosion corrosion performance of the processed specimens. The other reason could be due to the formation of oxide layer (Tio2) on the surface which resists corrosive attack. Grain refinement due to ECAP has high density of grain boundaries and dislocations inside grains which are the sites for passive films nucleation. Hence, the passivation layer for UFG/NSG Ti are formed much faster and the bond strength of oxide layer to the surface is stronger as compared to CG Ti [16-18].

Therefore if the oxide layer are damaged by the action of erosion the repair of passive layer take place faster and the rate E$\mathrm{C}$ is reduced. Here, it is also true that uneven distribution of strain which is result of induced stress can accelerates the corrosion rate, hence specimens with highest homogeneity are most resistance to the corrosion. Similar trend was observed when studying the effect of time on erosion corrosion of ECAPed copper [12-13].

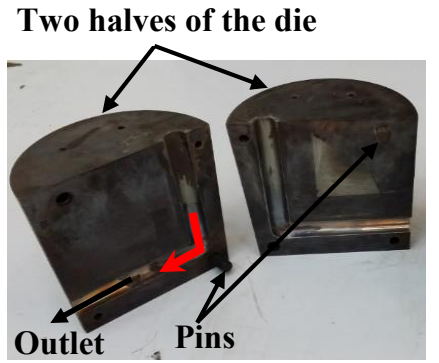

Fig. 1. Two halves ECAP die

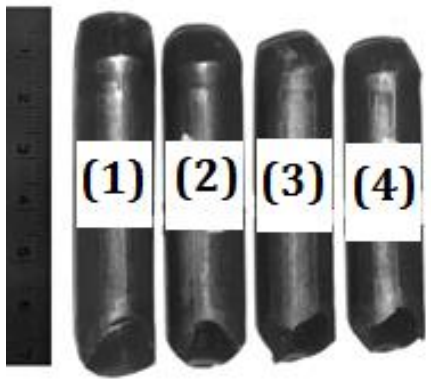

Fig. 2. Titanium samples after ECAP passes

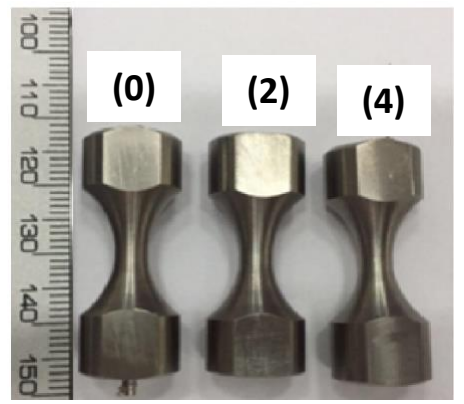

(a)
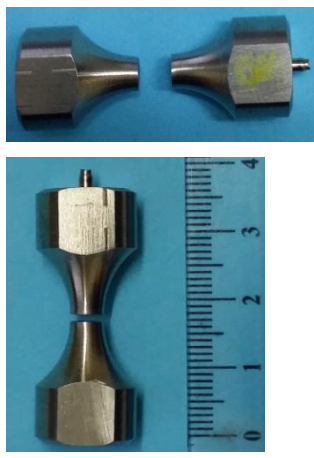

(b)

Fig. 3. CP-Ti Torsion specimen: (a) before torsion test: (0) annealed, (2) 2 pass ECAP, and (4) 4 pass ECAP

(b) After failure due to torsion 


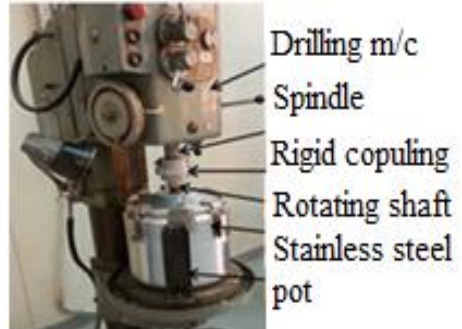

(a)

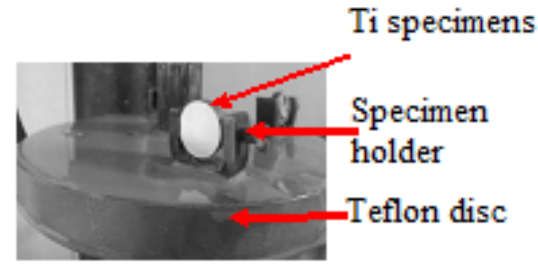

(b)

Fig. 4. a) Setup of slurry pot tester and, b) specimen holder for investigation of E-C of CP-Ti.

a)

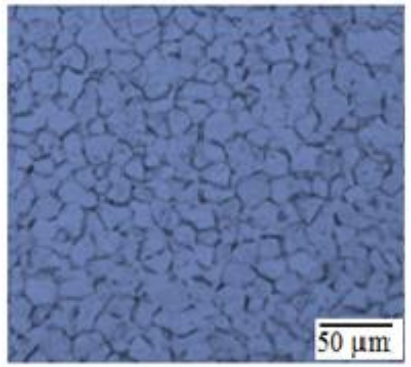

b)

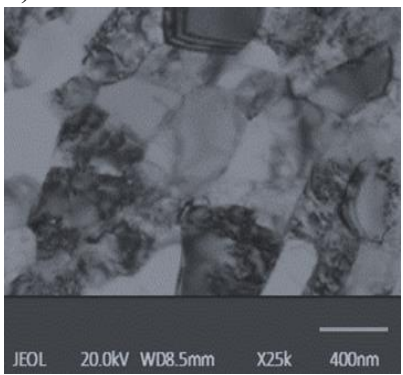

Fig. 5. Microstructure of CP-Ti (a) Annealed (b) After four ECAP passes

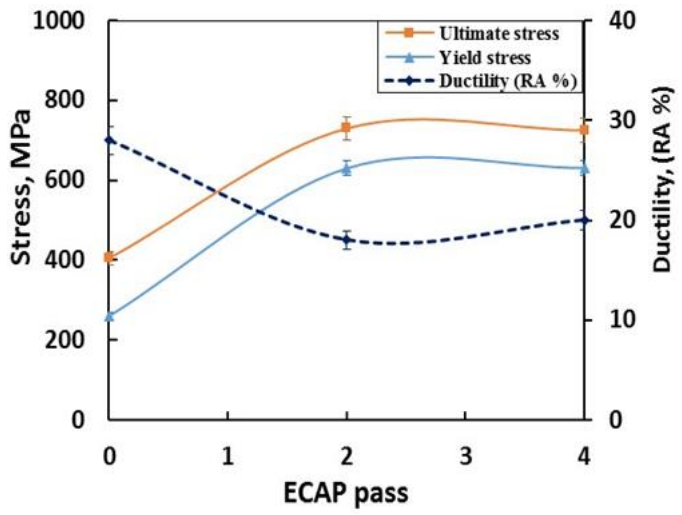

Fig. 6. The Ultimate shear stress, shear yield stress, and ductility of $\mathrm{CP}-\mathrm{Ti}$ as a function of ECAP passes 


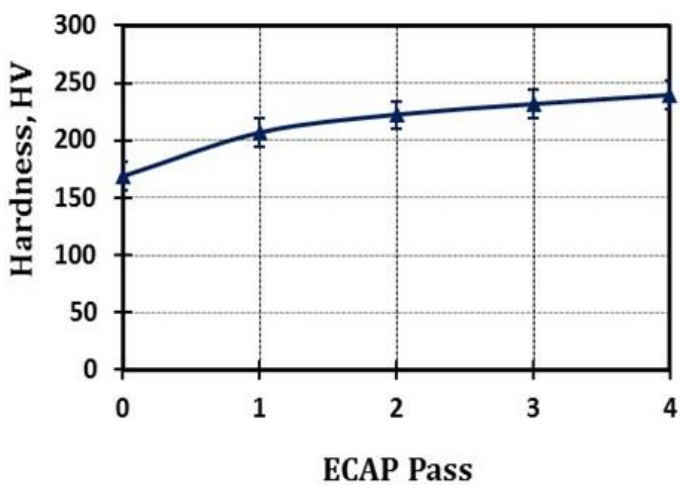

Fig. 7. Effect of ECAP passes on Vickers hardness of CP-Ti

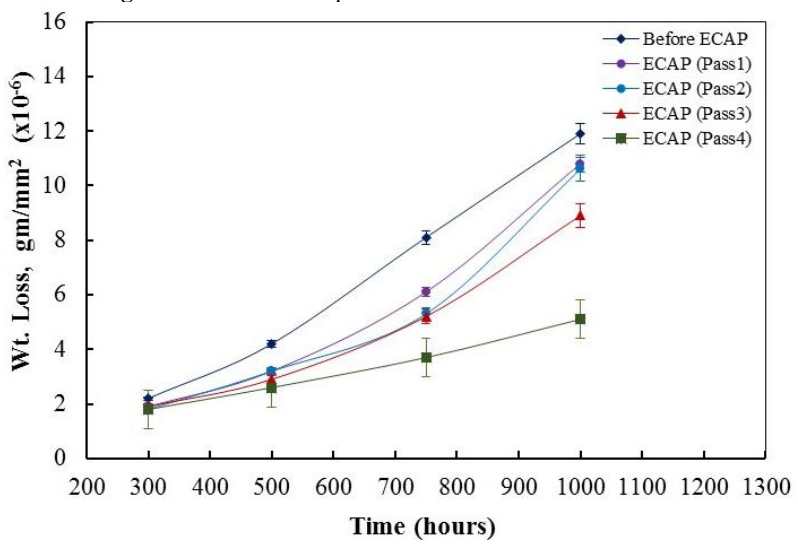

Fig. 8. Weight loss versus time of experiment for different ECAP passes $(\mathrm{v}=5 \mathrm{~m} / \mathrm{s}$, Impacting angle $=45 \mathrm{o}$, simulated body fluid)

\section{CONCLUSIONS}

In this work, set of experiments was conducted to examine the effect of ECAP passes on the mechanical property and strain homogeny of commercial pure titanium (CP-Ti). Furthermore, the role of strain homogeneity on erosion corrosion behavior of commercial pure titanium in a simulated body fluid was investigated through weight loss. The samples was pressed at elevated temperature $\left(400^{\circ} \mathrm{C}\right)$ by ECAP (route BC) up to four passes to achieve the Nano structure grain size. The following conclusions can be made from the current work:

1) $\mathrm{CP}-\mathrm{Ti}$ was successfully processed up to four passes by ECAP at $400^{\circ} \mathrm{C}$. Neither damage nor failure was observable on the samples after processing.

2) $\mathrm{HV}$ testing showed after four ECAP passes the average (HV) hardness increased by $50 \%$ as compared to annealed condition.

3) Results of torsion test showed that the yield and ultimate shear stresses increased by $65 \%, 16 \%$ and the ductility of the material decreased by $30 \%$ after four passes of ECAP, respectively.

4) Optical microscopy, SEM, and TEM images showed that the microstructure is more refined with increasing number of ECAP passes. The grain size of the CP-Ti was reduced from $\sim 30 \mu \mathrm{m}$ in the annealed condition to $\sim 300$ $\mathrm{nm}$ after four passes of ECAP. In addition, homogeneous ultra-fine grained microstructure was observed after four ECAP passes.

5) The E-C resistance of UFG/NSG CP-Ti is believed improved by a combination of a) grain refinement and texture, b) hardness increment which resulted in an increase of flow stress caused by strain hardening and strain rate 
hardening during SPD process, c) faster formation and stronger bond layer of oxide layer $\left(\mathrm{Tio}_{2}\right)$ on the surface and d) material homogeneity.

\section{ACKNOWLEDGMENTS}

The authors would like to acknowledge the financial support received from King Abdul-Aziz City for Science and Technology (KACST) for this work under Grant No. 35-89.

\section{REFERENCES}

1. A Neville and B A B McDougall. Proc Instn Mech Engrs Vol 216 Part L: J Materials: Design and Applications. (2002) pp 31-41.

2. Douglas C. H. Metal Corrosion in the Human Body: The Ultimate Bio-Corrosion Scenario. The Electrochemical Society Interface. (2008) 31-34.

3. Valiev R. Z., Alexandrov I. V., and Logos M. (2015). Nanostructured Materials Produced by Severe Plastic Deformation. Journal of Surface Engineered Materials and Advanced Technology.5 (1): 6.

4. A. Zhilyaev, N. Parkhimovich, G. Raab, V. Popov and V. Danilenko. Rev. Adv. Mater. Sci. 43 (2015) 61 - 66.

5. M Ebrahimi, Sh Attarilar, F Djavanroodi, C Gode, HS Kim, Materials and Design 63 (2014) 531-537

6. M. Borhani, F. Djavanroodi, Materials Science and Engineering A 546 (2012) 1-7.

7. F. Djavanroodi, A. A. Zolfaghari, M. Ebrahimi, K. Nikbin. Acta Metallurgica Sinica (English Letters) 27 (2014) 95100

8. F. Djavanroodi, H. Ahmadian, K. Koohkan, R. Naseri, Ultrasonics 53 (2013) 1089-1096.

9. XinbaYaer, Kazumichi Shimizu, Hideto Matsumoto, Tadashi Kitsudo, Tadashi Momono, Wear, 2008, vol. 264(11-12), pp 947-957.

10. Y. Liu, Y. F. Cheng, J. of Materials Engineering and Performance, 2011, vol. 20(2), pp 271-275.

11. Mar'ia-Dolores Berm'udez, Francisco J. Carri'on, Gin'es Mart'inez-Nicol'as, Rosa L'opez, Wear 258 (2005) 693-700

12. O. M. Irfan, S. M. S. Mukras, F. A. Al-Mufadi, F. Djavanroodi, Metals, 2017, vol. 7, pp 155.

13. O. M. Irfan, F. Al-Mufadi, Y. Al-Shataif, F. Djavanroodi, Applied Sci., 2017, vol. 7, 1250.

14. T. Sakai, A. Belyakov, R. Kaibyshev, H. Miura, J.J. Jonas, Prog. Mater. Sci. 60 (2014) 130-207.

15. S.W. Chung, H. Somekawa, T. Kinoshita, W.J. Kim, K. Higashi, Scr. Mat. 50 (2004) 1079-1083,

16. Balyanov, J. Kutnyakova, N.A. Amirkhanova, V.V. Stolyarov, R.Z. Valiev,X.Z. Liao, Y.H. Zhao b, Y.B. Jiang c, H.F. Xu c, T.C. Lowe b, Y.T. Zhu b, Scripta Materialia 51, 2004, 225-229

17. Jinwen Lu, Yong Zhang, Wangtu Huo, Wei Zhang, Yongqing Zhao, Yusheng Zhang, Applied Surface Science 434, 2018, 63-72

18. A. Balakrishnana, B. C. Lee, T. N. Kim and B. B. Panigrahi, Trends Biomater. Artif. Organs, Vol 22(1), 2008, pp 5464. 